\title{
A fatal case of pulmonary nocardiosis
}

\author{
Mahantesh Patil, ${ }^{1}$ Shivaprasad C, ${ }^{2}$ Jaicob Varghese, ${ }^{3}$ Natarajan Rajagopalan ${ }^{4}$ \\ ${ }^{1}$ Critical Care Department, Narayana Hrudayalaya Hospital, Bangalore, India; \\ ${ }^{2}$ Critical Care Services Department, Narayana Hrudayalaya Hospital, Bangalore, India; \\ ${ }^{3}$ Critical Care Medicine Department, Narayana Hrudayalaya Hospital, Bangalore, Karnataka, India; \\ ${ }^{4}$ Pulmonology and Critical Care Department, Narayana Hrudayalaya Hospital, Bangalore, India \\ Correspondence to Dr Natarajan Rajagopalan, gopanya@hotmail.com
}

\begin{abstract}
Summary
Pulmonary nocardiosis is a serious, most often considered an opportunistic infection affecting the respiratory tract. Even though it is more common in immunocompromised hosts, it is not infrequently seen in immunocompetent patients as well. The aerosol route is the main portal of entry in to the body. Molecular techniques have revolutionised the identification of Nocardia species. However such tests are limited to referral laboratories. The radiographic appearances of Nocardia infection vary from a small nodule to bilateral infiltrates with cavitation. Traditionally sulphonamides have been considered the treatment of choice. However, resistance to sulphonamides is increasingly recognised. Carbapenems and linezolid have been found to be uniformly active against all the pathogenic species of Nocardia that affect human beings. The authors report a case of pulmonary nocardiosis in an immunocompetent patient, in whom the infection relentlessly progressed to florid sepsis despite prompt institution of right antibiotics. Florid sepsis relating to pulmonary nocardiosis is rare.
\end{abstract}

\section{BACKGROUND}

Pulmonary nocardiosis is caused by aerobic gram positive bacilli which are ubiquitous in nature, primarily present in the soil. It is one of the well-known causes of opportunistic infection affecting the respiratory tract. Most reported cases have occurred in transplant patients. However approximately $50 \%$ of the patients who develop pulmonary nocardiosis have no underlying medical condition. The current incidence of nocardiosis is not known, but is believed to be on the increase. Drug resistance patterns of Nocardia have recently been elucidated. ${ }^{1}$ As a result the treatment choices have become more complex. We report a patient with pulmonary nocardiosis who had a rapidly progressive course culminating in septic shock despite early institution of appropriate treatment. Bacterial cultures for other pathogenic organisms were negative. Florid sepsis relating to pulmonary nocardiosis is rare.

\section{CASE PRESENTATION}

A 47-year-old obese male with type 2 diabetes mellitus, dilated cardiomyopathy with severe left ventricular dysfunction, bronchial asthma, presented to our hospital with history of low grade fever, productive cough and left-sided pleuritic chest pain of 4 days duration. On initial evaluation, the patient was afebrile with stable vital signs. Left lower lobe crakles were noted. There was no left pleural friction rub.

\section{INVESTIGATIONS}

Chest $\mathrm{x}$-ray revealed left lower lobe consolidation (figure 1). Initial laboratory findings revealed leukocytosis of $24000 / \mathrm{cmm}$ with neutrophilic predominance with normal kidney and liver functions. Sputum cultures grew Nocardia. Arterial blood gases on admission and subsequently were as shown in table 1.

\section{DIFFERENTIAL DIAGNOSIS}

Based on clinical presentation, a diagnosis of community acquired pneumonia was entertained. As patient had significant comorbid conditions such as diabetes, cardiomyopathy and pre-existing asthma, possibility of opportunistic infection was also considered.

\section{TREATMENT}

The patient was placed on ceftriaxone and azithromycin after sending appropriate cultures. On day 2 of admission,

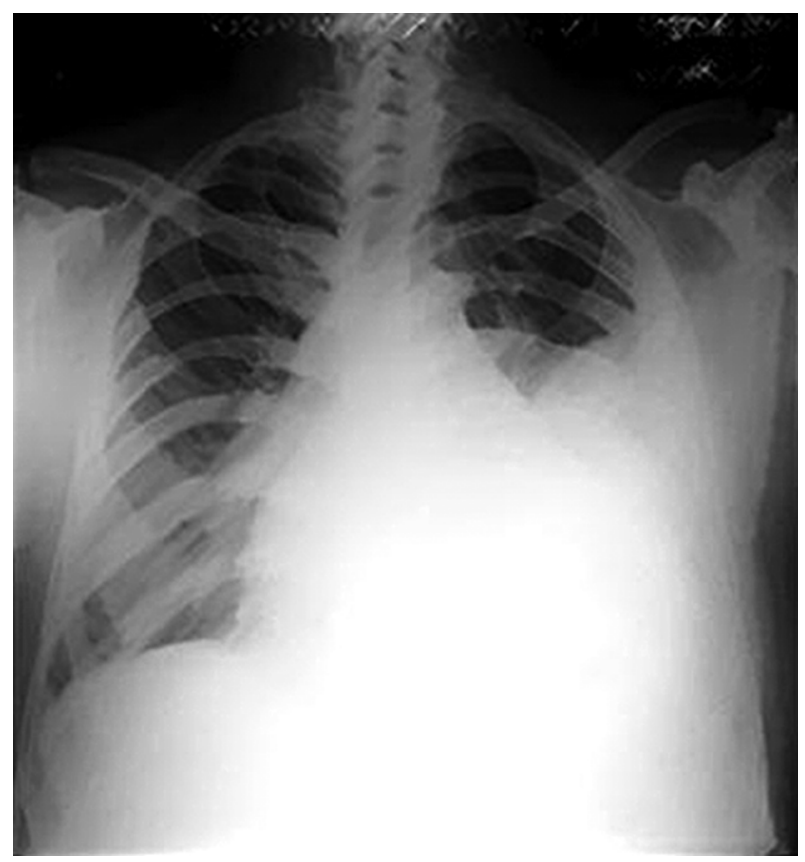

Figure 1 Chest x-ray showing left lower lobe pneumonia on presentation. 
Table 1 Serial ABGs showing progressive hypoxaemia and metabolic acidosis

\begin{tabular}{|c|c|c|c|c|c|}
\hline Date & $16 / 03 / 11$ & 19/03/11 & 19/03/11 & 19/03/11 & 20/03/2011 \\
\hline Time & $22: 45$ & 8:04 & $17: 30$ & $21: 48$ & 7:51 \\
\hline $\mathrm{PO}_{2}$ & 63.1 & 61.9 & 75.1 & 60.4 & 78 \\
\hline $\mathrm{PCO}_{2}$ & 28.3 & 32.8 & 34 & 50.1 & 42.5 \\
\hline $\mathrm{pH}^{2}$ & 7.478 & 7.329 & 7.304 & 7.180 & 7.12 \\
\hline tHB & 14.3 & 12.3 & 12.8 & 13.5 & 12.2 \\
\hline $\mathrm{SO}_{2} \%$ & 92.6 & 87.5 & - & - & - \\
\hline $\mathrm{Na}$ & 130 & 121 & 124 & 127 & 127 \\
\hline $\mathrm{K}$ & 4.49 & 4.9 & 4.9 & 4.70 & 5.11 \\
\hline $\mathrm{Cl}$ & 98 & 92 & - & - & - \\
\hline BE & -1.7 & -8 & -7.7 & -10.1 & -9.9 \\
\hline $\mathrm{HCO}_{3}$ & 26 & 18 & 18.2 & 16.4 & 16.6 \\
\hline $\mathrm{FiO}_{2}{ }^{\circ}$ & $21 \%$ & $\begin{array}{l}\text { On non-rebreating mask } \\
6 \text { I oxygen }\end{array}$ & On NIV, $10 \mathrm{LO}_{2}$ & $\mathrm{PCV}, 100 \% \mathrm{O}_{2}$ & PCV mode with $100 \% \mathrm{O}_{2}$ \\
\hline Events correlation & On admission & $\begin{array}{l}\text { On the morning of day, of } \\
\text { worsening }\end{array}$ & With NIV support & $\begin{array}{l}\text { Got intubated due to } \\
\text { worsening condition }\end{array}$ & $\begin{array}{l}\text { On stiff inotropic support } \\
\text { and CRRT on fateful day }\end{array}$ \\
\hline Impression & $\begin{array}{l}\text { Mild Hypoxia. A-a } \\
\text { gradient high }\end{array}$ & $\begin{array}{l}\text { Hypoxia, worsening } \\
\text { metabolic acidosis }\end{array}$ & $\begin{array}{l}\text { Worsening metabolic } \\
\text { acidosis }\end{array}$ & $\begin{array}{l}\text { Mixed metabolic and } \\
\text { respiratory acidosis }\end{array}$ & \\
\hline
\end{tabular}

CRRT, continuous renal replacement therapy; NIV, non-invasive ventilation; PCV, pressure controlled ventilation.

we were alerted by the microbiology team regarding presence of the gram positive, branching, beaded bacilli with possible diagnosis of pulmonary nocardiosis (figure 2). Trimethoprim - sulphamethoxazole was added to the treatment regimen.

On the third day of admission, the patient became more tachypneic and hypoxic. He was shifted to medical ICU and was initially placed on non-invasive ventilation (NIV). His condition deteriorated to overt sepsis requiring fluid resuscitation and pressors. Because of tenuous haemodynamics and worsening gas exchange the patient was intubated and mechanically ventilated. Antibiotics were escalated to imipenem and linezolid in addition to the trimethoprimsulphamethaxazole. Ceftriaxone and azithromycin were discontinued. The patient was adequately covered with hydrocortisone for possible adrenal deficiency. CT thorax showed left lower lobe airspace consolidation and a leftsided pleural effusion (figure 3). Blood cultures confirmed the presence of nocardiosis.

Haemodialysis was started for renal failure on day 4 of admission. A chest tube was inserted to drain a left-sided pleural effusion (figure 4).

\section{OUTCOME AND FOLLOW-UP}

In spite of early institution of antibiotics and resuscitative measures patients' condition deteriorated and progressed to multi-organ dysfunction syndrome. He died on the 6th hospital day.

\section{DISCUSSION}

Nocardia are ubiquitous soil dwelling gram-positive bacteria that are responsible for a wide-spectrum of disease in patients. Nocardiosis is more common among the immunocompromised; particular risk factors include transplantation (solid organ or bone marrow), AIDS (CD4 count usually less than 50 cells $/ \mathrm{ml}$ and not on Pneumocystis jiroveci prophylaxis with trimethoprim and sulfamethoxazole), ${ }^{2}$ glucorticoid use, underlying malignancy, intravenous drug abuse (from contaminated needles) and underlying pulmonary disease. Infection occurs more commonly in males, ${ }^{2}$ and is less common in paediatric age group. Our patient

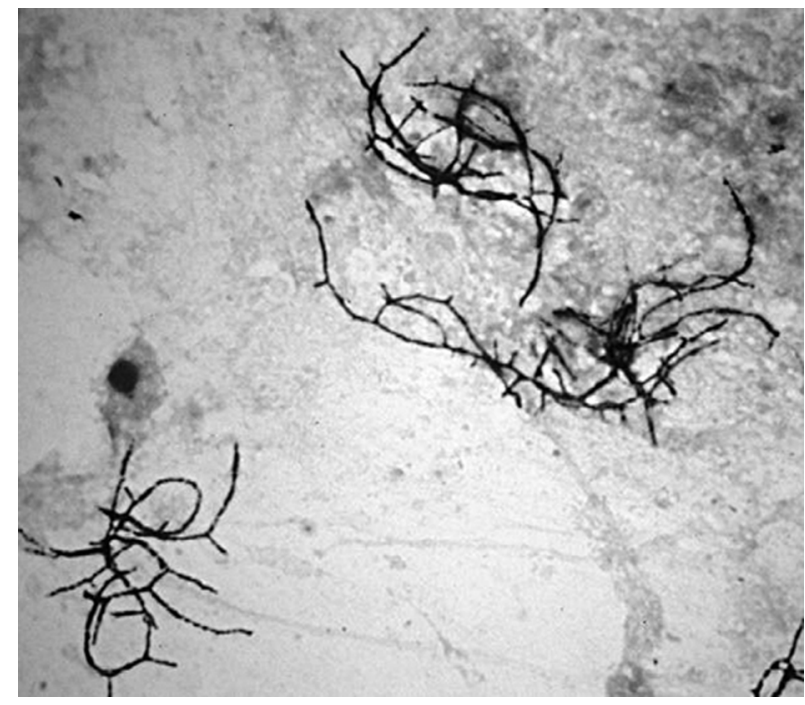

Figure 2 Gram positive, branching, beaded bacilli.

was a farmer by occupation and is likely to have had exposure to Nocardia. He also suffered from mild persistent asthma but was not on regular inhaled corticosteroid.

As Nocardia is not considered to be a normal oropharyangeal or bronchopulmonary commensal, the isolation of Nocardia from a sputum specimen is nearly always a significant finding. ${ }^{3}$ The aerosol route is the main portal of entry into the body, and the lungs are the most common sites of infection. Species that produce pulmonary or disseminated infection include Nocardia asteroids, $N$ abcessus, $N$ farcinica, $N$ pseudobrasiliensis, $N$ transvalensis, $N$ nova, $N$ otitisdiscaviarium, $N$ Africana, $N$ asiatica, $N$ beijingensis, $N$ cyriacigerorgica, $N$ higoensis, $N$ paucimouans. In our patient, the sputum smear showed abundant gram positive, branching and beaded bacilli. Treatment was initiated based on smear report. Later the cultures did show Nocardia.

Correct identification of species is important for clinical management and treatment and for epidemiological purposes. Molecular techniques, such as $\mathrm{PCR}$, restriction enzyme analysis and 16S RNA gene sequencing, have 


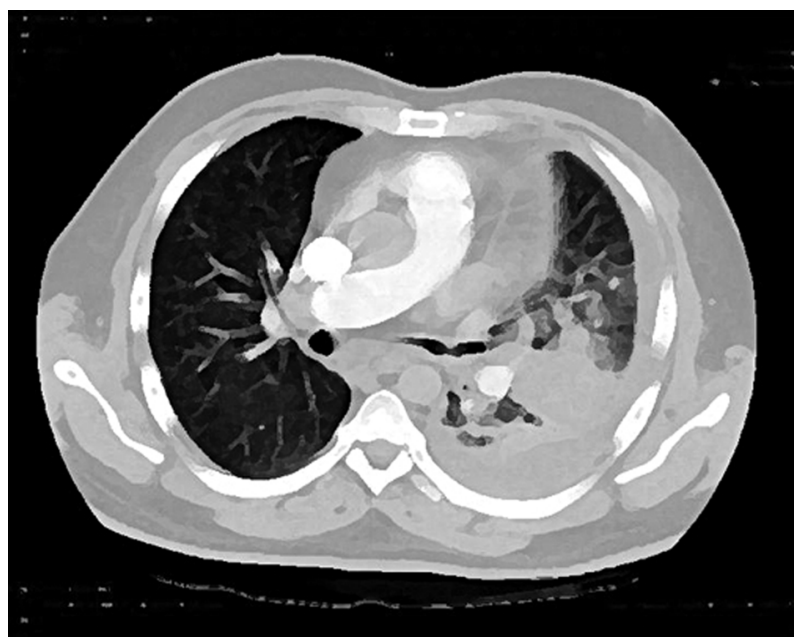

Figure 3 CT thorax showing left lower lobe pneumonia with effusion.

revolutionised the identification of Nocardia species. These techniques are, however, restricted to referral laboratories. We could not speciate the organism in our patient as the facility was not available. ${ }^{4}$

The radiographic appearance of Nocardia infection reported shows wide range of findings. Parenchymal disease may range from a small nodule to bilateral infiltrates with cavitations. Nocardia tends to produce necrotising, poorly contained pneumonia and sometimes result in erosion into adjacent bony structures, resulting in misdiagnosis of malignancy. Upper lobe disease is common, and these patients are often considered to have tuberculosis before the culture results are confirmed, as Nocardia is weakly acid-fast positive. ${ }^{5}$ Concomitant pleural effusions occur in $10-33 \%$ of cases. ${ }^{5}$ Our patient also developed significant pleural effusion requiring drainage.

Historically, sulphonamides have been the treatment of choice. A high percentage of organisms are still sensitive to this antibiotic. However, it should be kept in mind that resistance to sulphonamides is on the rise especially among $N$ farcinica and $N$ otitisdiscavaiarium isolates. ${ }^{6}$

In patients with pulmonary nocardiosis and dissemination to other organs, especially the CNS, combined treatment is recommended consisting of sulphonamides and a bactericidal primary agent. Experimental studies have shown in vitro synergy with imipenem-cefotoxime, cefotoxime-amikacin and imipenem-amikacin with good clinical results. ${ }^{7}$ Linezolid has shown excellent invitro activity against Nocardia. Unfortunately, the high cost and serious toxicities associated with prolonged use has limited its use to as a salvage therapy. ${ }^{8}$

Duration of treatment is a subject of debate. Immunocompitant patients with pulmonary nocardiosis and disseminated nocardiosis outside CNS should be treated for 6-12 months. In case of immunosuppressed patients the treatment should continue for 1 year and if possible the immunosuppressant drug should be reduced. Likewise, the duration of treatment must be at least 1 year for patients with CNS involvement.

In a recently published review on nocardiosis, mortality was $38.7 \%$, increasing to $64 \%$ in disseminated nocardiosis and $100 \%$ in the event of CNS infection. ${ }^{9}$ Therefore all

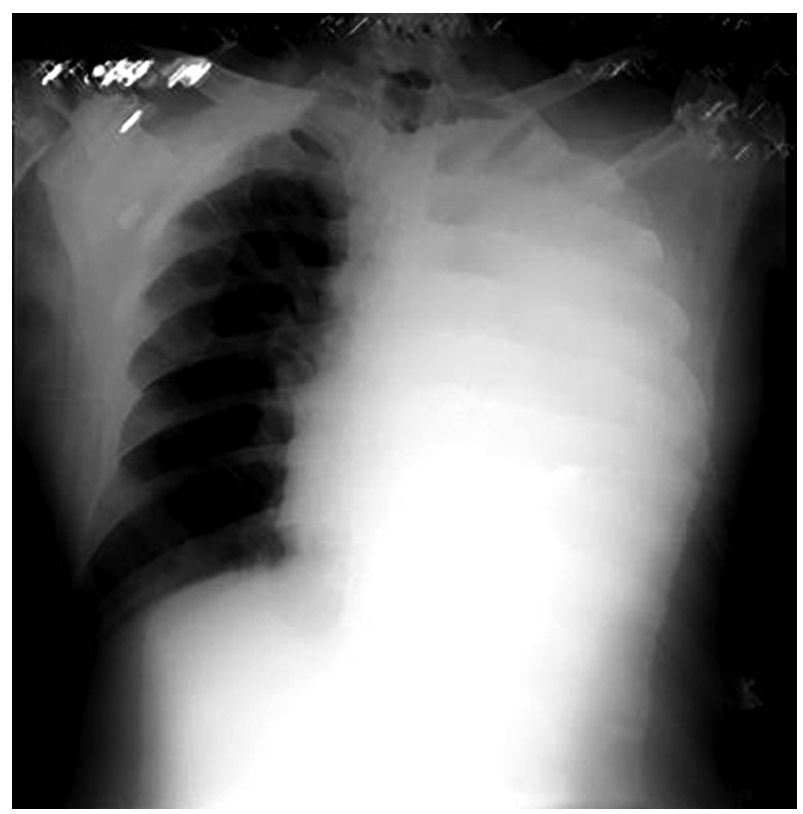

Figure 4 Chest x-ray showing progression to massive pleural effusion on left side.

patients with pulmonary nocardiosis should be screened for disseminated disease.

The unique feature of this case presentation is that patient went in to refractory septic shock despite appropriate antibiotics. Bacterial cultures for other pathogenic organisms were negative. Florid sepsis relating to pulmonary nocardiosis is rare.

\section{Learning points}

- Nocardia infection has a high mortality. Its incidence is underestimated because it takes more than 3 days and sometimes up to 7 days to grow in culture media. The physician treating the patient should alert the microbiology team regarding the possibility of Nocardia infection so that cultures can be maintained for at least 1 week.

- Physicians have to maintain a high degree of suspicion especially in immunocompromised patients.

- With the emerging resistance to some of the conventional antibiotics such as sulphonamides, microbiology laboratories should try and speciate the organism and provide sensitivity reports to help the treating physician to institute appropriate antibiotics. This might also help us in understanding the epidemiology of this unique organism.

\section{Competing interests None}

Patient consent Obtained.

\section{REFERENCES}

1. Uhde KB, Pathk S, McCullum I Jr. Antimicrobial-resistant nocardia isolates, United States, 1995-2004. Clin infect Dis 2010;51:1445-8.

2. Uttamchandani RB, Daikos GL, Reyes RR, et al. Nocardiosis in 30 patients with advanced human immunodeficiency virus infection: clinical features and outcome. Clin Infect Dis 1994;18:348-53. 


\section{BMJ Case Reports}

3. Brown-Elliott BA, Brown JM, Conville PS, et al. Clinical and laboratory features of the Nocardia spp. based on current molecular taxonomy. Clin Microbiol Rev 2006;19:259-82.

4. Wauters G, Avesani V, Charlier J, et al. Distribution of nocardia species in clinical samples and their routine rapid identification in the laboratory. J Clin Microbiol 2005;43:2624-8.

5. Kramer MR, Uttamchandani RB. The radiographic appearance of pulmonary nocardiosis associated with AIDS. Chest 1990;98:382-5.

6. Yildiz 0, Alp E, Tokgoz B, et al. Nocardiosis in a teaching hospital in the Central Anatolia region of Turkey: treatment and outcome. Clin Microbiol Infect 2005;11:495-9.
7. Gombert ME, Aulicino TM. Synergism of imipenem and amikacin in combination with other antibiotics against Nocardia asteroides. Antimicrob Agents Chemother 1983;24:810-11.

8. Jodlowski TZ, Melnychuk I, Conry J. Linezolid for the treatment of Nocardia spp. infections. Ann Pharmacother 2007;41:1694-9.

9. Martinez R, Reyes S, Menendez R. Pulmonary nocardiosis: risk factors, clinical features, diagnosis and prognosis. Curr Opin Pulm Med 2008;14:219-27.

This pdf has been created automatically from the final edited text and images.

Copyright 2012 BMJ Publishing Group. All rights reserved. For permission to reuse any of this content visit http://group.bmj.com/group/rights-licensing/permissions.

BMJ Case Report Fellows may re-use this article for personal use and teaching without any further permission.

Please cite this article as follows (you will need to access the article online to obtain the date of publication).

Patil M, C S, Varghese J, Rajagopalan N. A fatal case of pulmonary nocardiosis. BMJ Case Reports 2012;10.1136/bcr.09.2011.4875, Published XXX

Become a Fellow of BMJ Case Reports today and you can:

- Submit as many cases as you like

- Enjoy fast sympathetic peer review and rapid publication of accepted articles

- Access all the published articles

- Re-use any of the published material for personal use and teaching without further permission

For information on Institutional Fellowships contact consortiasales@bmjgroup.com

Visit casereports.bmj.com for more articles like this and to become a Fellow

Keep up to date with all published cases by signing up for an alert (all we need is your email address) http://casereports.bmj.com/cgi/alerts/etoc 